\title{
An Improved MPPT Algorithm for PV Generation Applications Based on $P-U$ Curve Reconstitution
}

\author{
Yaoqiang Wang, Meiling Zhang, and Xian Cheng \\ School of Electrical Engineering, Zhengzhou University, Zhengzhou 450001, China \\ Correspondence should be addressed to Xian Cheng; chengxian@zzu.edu.cn
}

Received 22 January 2016; Revised 26 May 2016; Accepted 29 May 2016

Academic Editor: Ahmed M. Massoud

Copyright (C) 2016 Yaoqiang Wang et al. This is an open access article distributed under the Creative Commons Attribution License, which permits unrestricted use, distribution, and reproduction in any medium, provided the original work is properly cited.

\begin{abstract}
The output power of PV array changes with the variation of environmental factors, such as temperature and solar irradiation. Therefore, a maximum power point (MPP) tracking (MPPT) algorithm is essential for the photovoltaic generation system. However, the $P-U$ curve changes dynamically with the variation of the environmental factors; here, the misjudgment may occur if a simple perturb-and-observe (P\&O) MPPT algorithm is used. In order to solve this problem, this paper takes MPPT as the main research object, and an improved MPPT algorithm for PV generation applications based on $P-U$ curve reconstitution is proposed. Firstly, the mathematical model of PV array is presented, and then the output dynamic characteristics are analyzed. Based on this, a $P-U$ curve reconstitution strategy is introduced, and the improved MPPT algorithm is proposed. At last, simulation and comparative analysis are conducted. Results show that, with the proposed algorithm, MPP is tracked accurately, and the misjudgment problem is solved effectively.
\end{abstract}

\section{Introduction}

It is universally acknowledged that photovoltaic power generation as a new green technology has become one of the hot spots at home and abroad. However, the output power of PV array is affected by the external environment factors strongly, such as temperature and solar irradiation. Therefore, in order to adjust the working performance, it is particularly important to output maximum power of PV array as much as possible.

There are many kinds of common MPPT control algorithms, and the control process is not the same, and the corresponding control effect is also different [1]. The commonly used algorithms include the method based on optimization mathematical model, the method based on the output control, the method based on intelligent control and nonlinear control, and the method based on perturbation of optimization [2].

The perturb-and-observe algorithm and incremental conductance algorithm are the important branches of the method based on perturbation of optimization which are the most commonly used methods currently [3]. The MPP is tracked by perturbing the output voltage of PV array with perturbation observation algorithm which is simple [4-8]. Nevertheless, the output voltage perturbation signal of PV array changes when solar irradiation changes strongly, so the power output characteristic deteriorates. The tracking accuracy is not high and oscillation and misjudgment phenomena easily occur. Incremental conductance algorithm is actually an improved perturb-and-observe algorithm [9-14], with which the MPP is tracked by incremental conductance and instantaneous conductance of PV array. In this method, the physical concept is clear. And, compared with what was mentioned above, the MPP can be tracked quickly with this method when solar irradiation changes. But misjudgment problem still exists, when solar irradiation mutates.

Until now, many scholars study the MPPT algorithm based on intelligent control and nonlinear control such as fuzzy algorithm [15], siding algorithm [16], Particle Swarm Optimization (PSO) [17], and genetic algorithm [18]. Although these algorithms do not need to establish accurate mathematical model of the controlled object, their control 


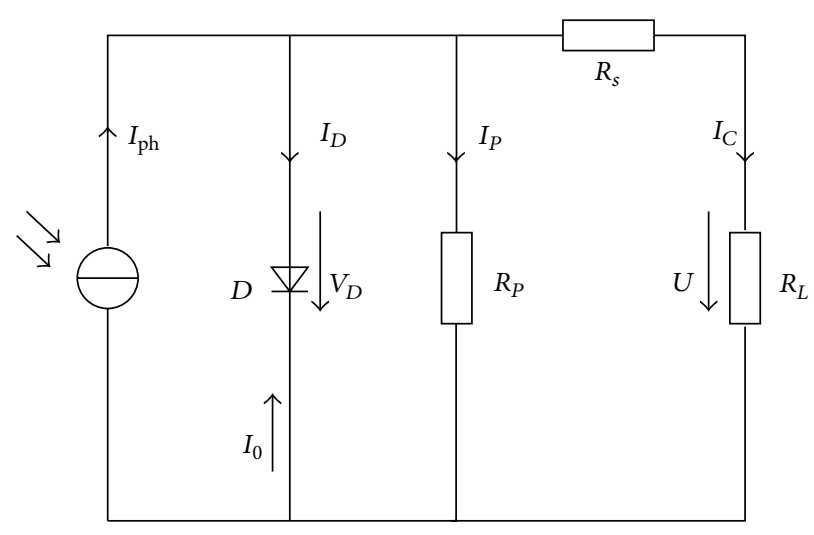

FIGURE 1: Equivalent circuit of photovoltaic cell.

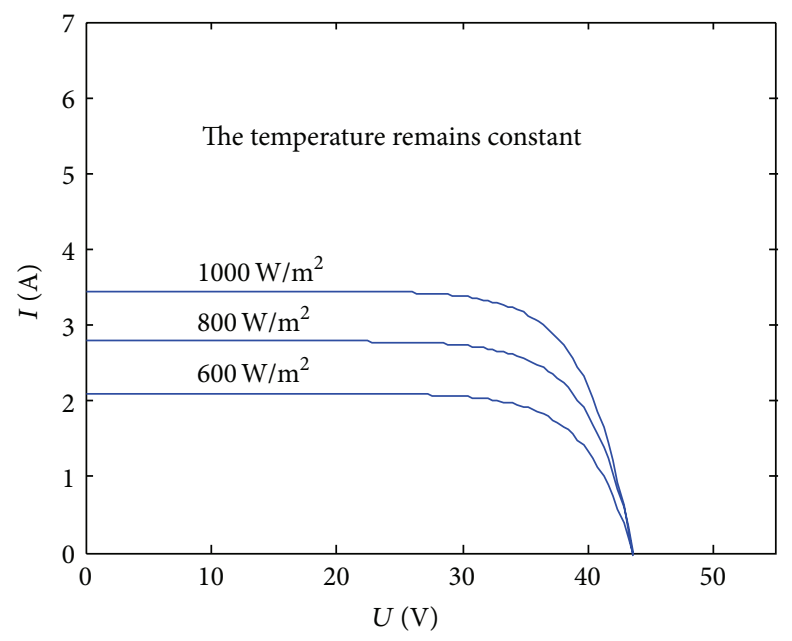

FIGURE 2: $U-I$ characteristic curves of PV cell with different solar irradiation values.

algorithms are generally more complicated and are not conducive to realization of the system and are not conducive to reduction of the unit costs as well.

In this paper, based on the mathematical model of $\mathrm{PV}$ array and classical perturb-and-observe algorithm, $P-U$ curve reconstitution is introduced to track the maximum power point accurately. Finally, the proposed MPPT control strategy is verified by simulation. Results show that the maximum power point is tracked accurately with the proposed MPPT algorithm, and the misjudgment is eliminated effectively, and the proposed MPPT algorithm also has a good dynamic performance.

\section{Mathematical Model of PV Array}

The photovoltaic cell is different from dry cell and battery; the latter can store the transformed energy. However, photovoltaic cell is a device based on photovoltaic effect which converts solar energy into electrical energy directly and immediately. Figure 1 shows an equivalent model of PV cell. When solar irradiation is constant, the photogenerated current $I_{\mathrm{ph}}$ does not change with the working state of the photovoltaic cell, so it can be seen as a constant current source. $R_{L}$ is the load added at both ends of the PV cell, and $U$ is the terminal voltage.

By Figure 1, the output current equation of the PV cell can be described as

$$
I_{C}=I_{S}-I_{0}\left\{\exp \left(\frac{q}{A K T} U\right)-1\right\}
$$

where $A$ is a $\mathrm{P}-\mathrm{N}$ junction coefficient of semiconductor devices in photovoltaic cells; $K$ is Boltzmann's constant; $q$ is unit charge; $T$ is absolute temperature; $I_{C}$ is output current; $I_{0}$ is diode reverse saturation current; $I_{S}$ is short-circuit current (the corresponding $I_{\mathrm{ph}}$ when $U$ is 0 in Figure 1).

As can be seen from (1), the output characteristic curves of PV cell change with external environment factors such as solar irradiation and temperature. Figure 2 shows $U-I$ characteristic curves when temperature is constant and solar irradiation changes. It can be seen that short-circuit current reduces significantly and open-circuit voltage is almost unchanged when solar irradiation decreases. Figure 3 shows $P-U$ characteristic curves with the same conditions. Similarly, it can be seen from the figure that $P-U$ characteristic curve has a single peak, and the maximum power point is its extreme point, and the output power increases with solar irradiation and reaches a maximum at a point. 


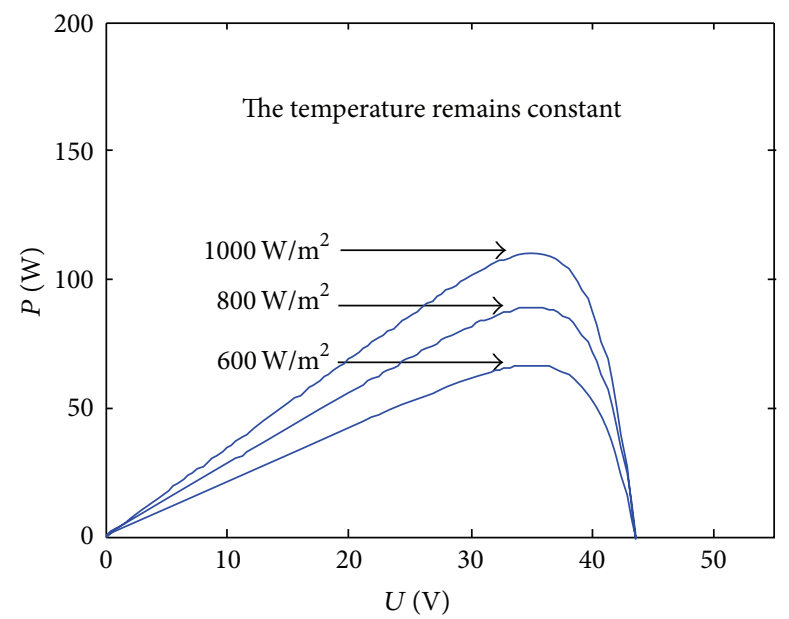

FIgURE 3: $P-U$ characteristic curves of PV cell with different solar irradiation values.

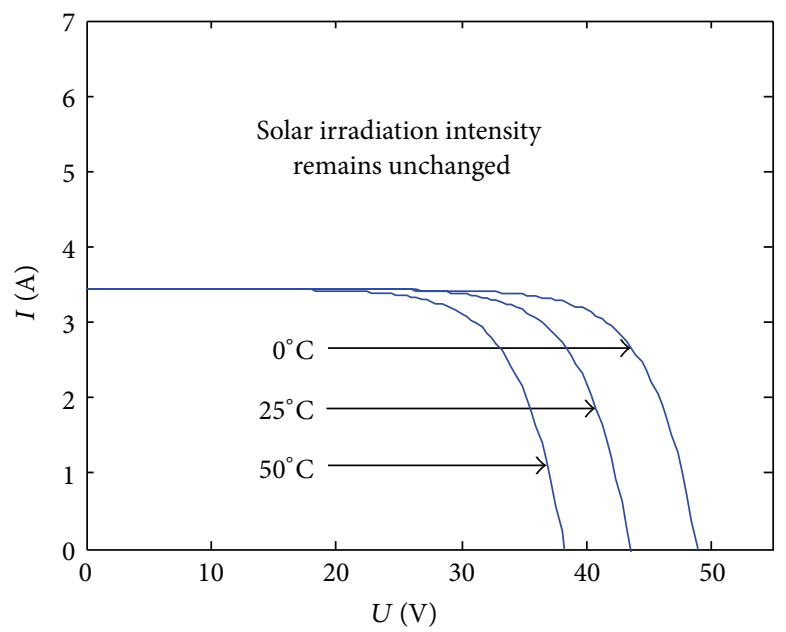

FIgURE 4: $U-I$ characteristic curves of PV cell at different temperatures.

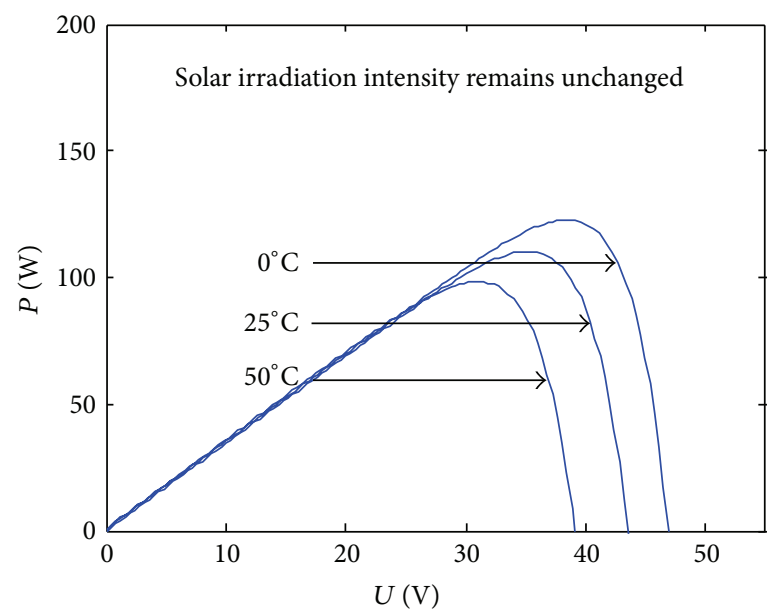

FIgURE 5: $P-U$ characteristic curves of PV cell at different temperatures. 


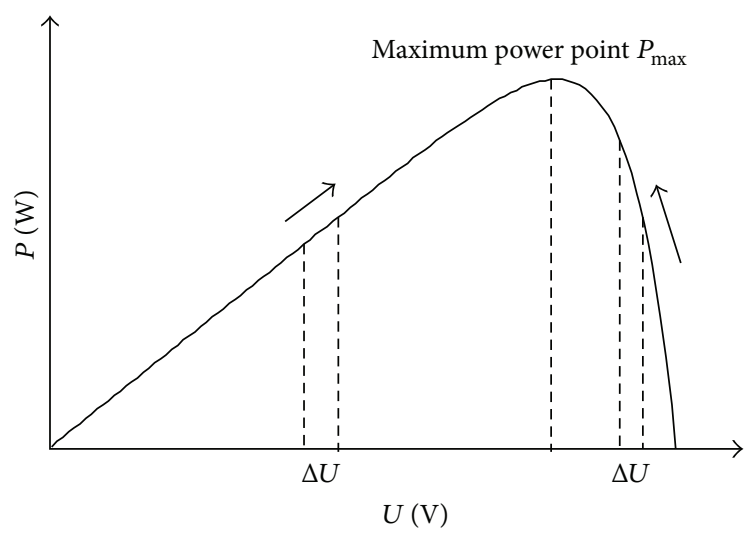

FIGURE 6: Schematic diagram of the classical perturb-and-observe algorithm.

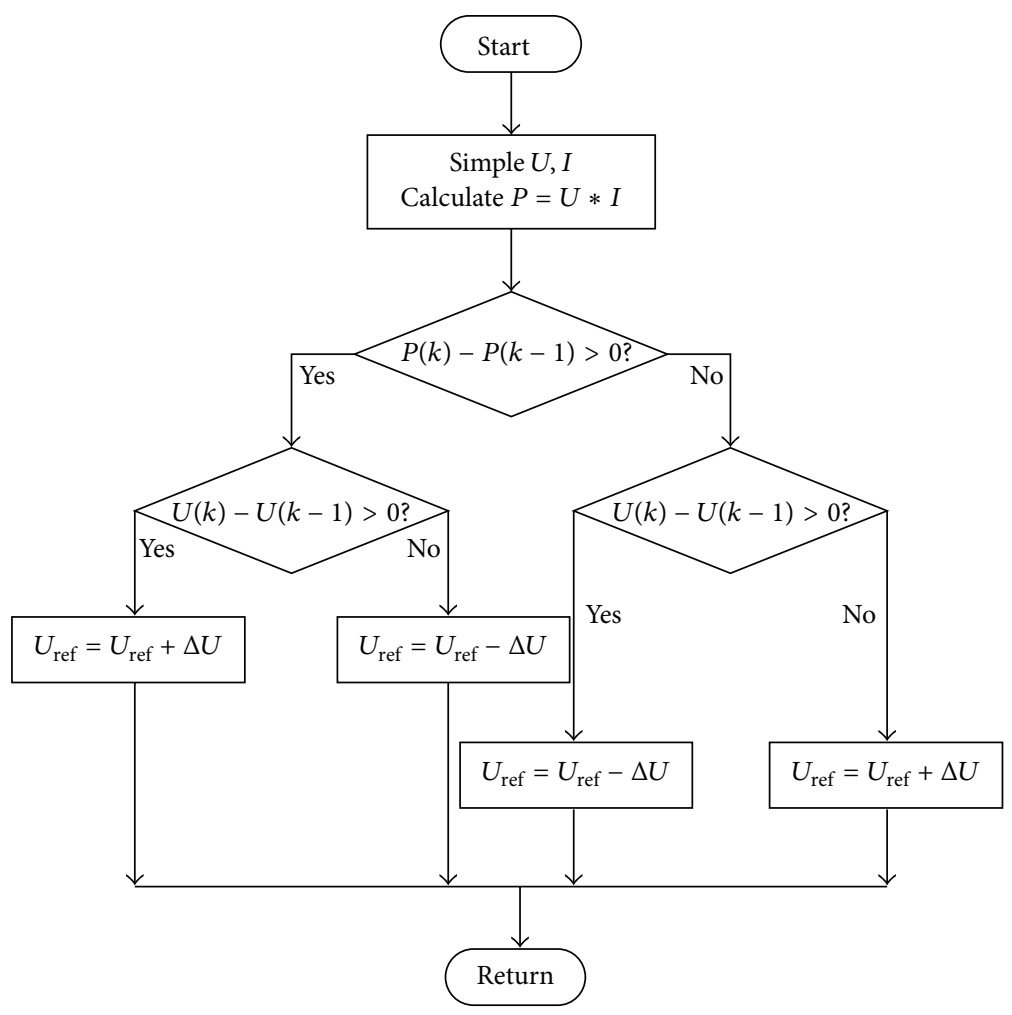

FIGURE 7: The flowchart of classical perturb-and-observe algorithm.

Keeping solar irradiation unchanged, when temperature changes, the output characteristic curves of PV array can be obtained which are shown in Figures 4 and 5. It can be seen from the two figures that open-circuit voltage increases significantly and short-circuit current is a constant when temperature decreases. The output power of PV array increases with the decrease of temperature and reaches the maximum at a certain point finally.

It can be seen from the output characteristic analysis of PV cell mentioned above that the output characteristic curves of PV array change with external environmental factors, such as solar irradiation and temperature. Therefore, MPPT algorithm is added in the operating control of PV power generation system to provide the maximum output power for load in different working conditions.

\section{Improved MPPT Algorithm Based on $P-U$ Curve Reconstitution}

3.1. Classical Perturb-and-Observe Algorithm. The working principle of classical perturb-and-observe algorithm is shown as in Figure 6, and step search is adopted in this method. Suppose that the external environmental factors remain unchanged, such as temperature and solar irradiation. $\Delta U$ is the voltage adjustment step, and $P_{\max }$ is the power of maximum power point. 


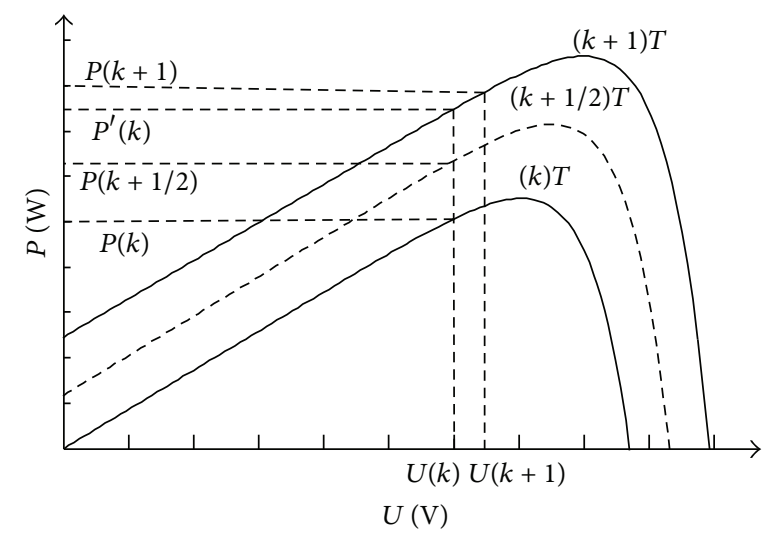

FIGURE 8: Power prediction schematic.

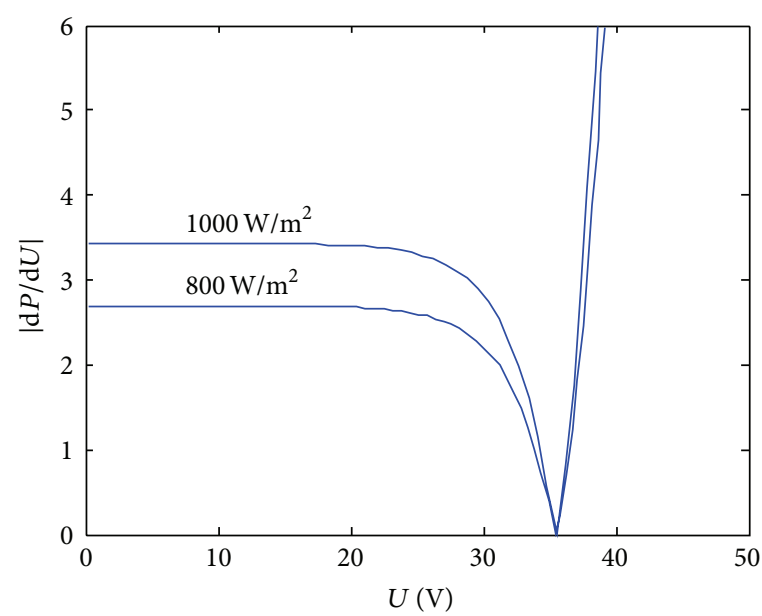

Figure 9: Relation curve of $|\mathrm{d} P / \mathrm{d} U|$ against voltage $U$.

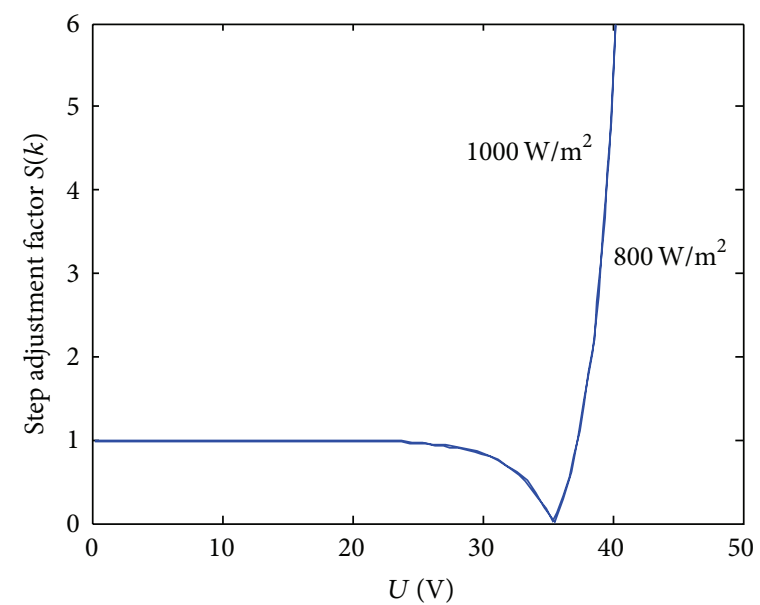

FIGURE 10: Relation curve of $S(k)$ against voltage $U$.

Firstly, an initial step is chosen; perturbation is started; on the basis of the working voltage, a forward perturbation step is added. Perturbation direction remains unchanged if the power increases; perturbation direction changes if the power reduces. Perturbation process is repeated as shown in Figure 6 until the maximum power point is tracked. Owing to the fact that the perturbation step has a large impact on tracking accuracy and speed, it should be selected appropriately.

The flowchart of classical perturb-and-observe algorithm is shown in Figure 7. $U(k)$ is the present voltage and $I(k)$ is the present current, and $P(k)$ is the corresponding power; $U(k-1)$ is the last voltage and $I(k-1)$ is the last current; $P(k-1)$ 


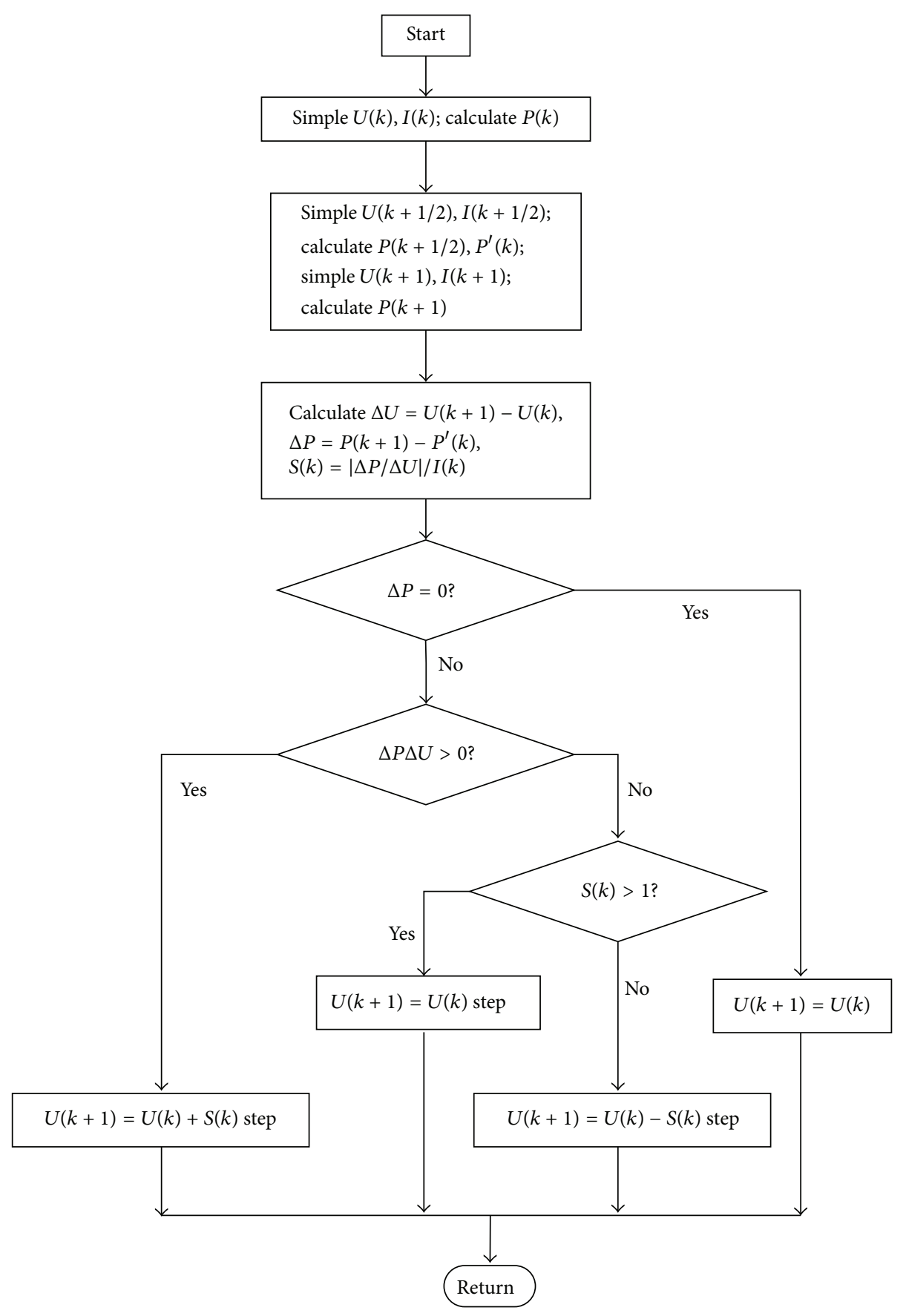

FIGURE 11: Flowchart of improved MPPT algorithm.

is the corresponding power; $U_{\text {ref }}$ is reference voltage; $\Delta U$ is voltage adjustment step.

Firstly, $\Delta P$ and $\Delta U$ can be described as

$$
\begin{aligned}
& \Delta P=P(k)-P(k-1), \\
& \Delta U=U(k)-U(k-1) .
\end{aligned}
$$

When $\Delta U$ is positive, if $\Delta P$ is also positive, which indicates that the current working point is on the left of the maximum power point, then it should be in the perturbation mode of increasing voltage; if $\Delta P$ is negative, which indicates that the current working point is on the right of the maximum power point, then it should be in the perturbation mode of decreasing voltage. When $\Delta U$ is negative, if $\Delta P$ is positive, which indicates that the current working point is on the right of the maximum power point, then it should be in the perturbation mode of decreasing voltage; if $\Delta P$ is negative, which indicates that the current working point is on the left of the maximum power point, then it should be in the perturbation mode of increasing voltage.

It should be noted that the working point oscillates on both sides of the maximum power point reciprocating due to 


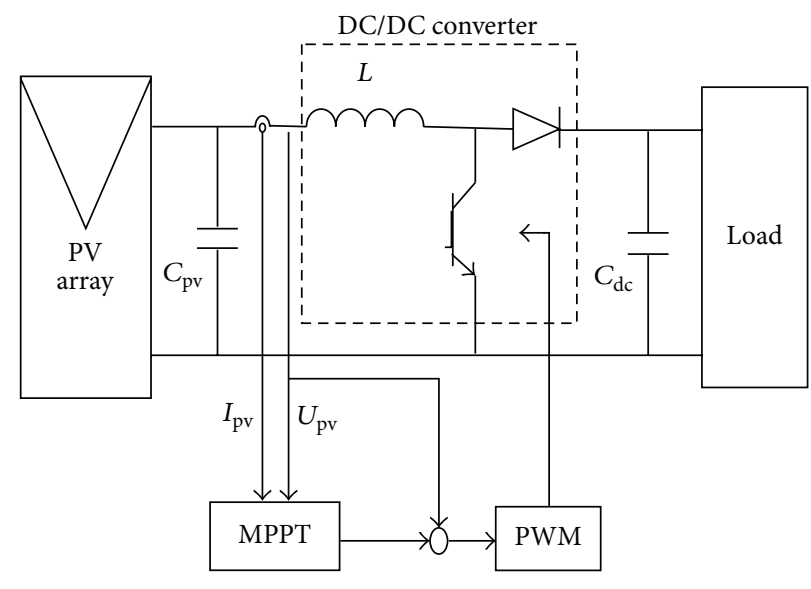

Figure 12: MPPT main circuit.

a fixed perturbation step, in which it is unable to be stabilized at the maximum power point, and sometimes misjudgment phenomenon occurs. When external conditions change, the output characteristic curves of PV array change dynamically. Thus, misjudgment may occur if a classical perturb-andobserve MPPT algorithm is used.

3.2. Improved MPPT Algorithm. In order to solve the misjudgment problem of classical $\mathrm{P} \& \mathrm{O}$ algorithm, power prediction is added, which ensures the power points are in the same $P-U$ curve before and after the perturbation.

Figure 8 shows a schematic diagram of power prediction. When the sampling frequency is high enough, assume that the change rate of solar irradiation in a sampling period is constant. Without voltage perturbation at $k T$, the power $P(k)$ is calculated. Then, the power $P(k+1 / 2)$ is calculated at $(k+1 / 2) T$, and the predicted power $P^{\prime}(k)$ can be obtained as follows:

$$
P^{\prime}(k)=2 P\left(k+\frac{1}{2}\right)-P(k)
$$

Then, $\Delta U$ is perturbed at $(k+1) T$, and the power is $P(k+1)$ when perturbation voltage is $U(k+1)$. The measured power $P(k+1)$ and the predicted power $P^{\prime}(k)$ are on the same $P-U$ characteristic curve at the same solar irradiation theoretically. Therefore, the proposed MPPT algorithm in this paper does not exhibit misjudgment problem.

At the same time, in order to solve the contradiction between the tracking accuracy and speed, a variable step is adopted. as

By (1), the output power of PV array can be approximated

$$
P=I_{S} U-I_{0} U\left\{\exp \left[\frac{q}{A K T} U\right]-1\right\} .
$$

Thus, the derivative of power with respect to voltage can be obtained as

$$
\frac{\mathrm{d} P}{\mathrm{~d} U}=I_{S}-I_{0} \exp \left[\frac{q}{A K T} U\right] *\left[1+\frac{q}{A K T} U\right]-I_{0} .
$$

Study shows that $|\mathrm{d} P / \mathrm{d} U|$ is suitable for perturbation step. Then, the curve of $|\mathrm{d} P / \mathrm{d} U|$ and voltage $U$ are shown in Figure 9. It shows that the curves are different when solar irradiation varies greatly, so it is difficult to get the normalized function of the perturbation step to achieve the above goal.

However, as shown in Figure 9, $|\mathrm{d} P / \mathrm{d} U|$ and short-circuit current are similar to the positive correlation on the left side of MPP. Therefore, in order to find the normalized function of voltage perturbation step, (3) can be divided by output current of PV array after the absolute value operation, which can be calculated as

$$
\begin{aligned}
S(k) & =\frac{1}{I}\left|\frac{\mathrm{d} P}{\mathrm{~d} U}\right| \\
& =\frac{1}{I}\left|I_{S}-I_{0} \exp \left[\frac{q}{A K T} U\right] *\left[1+\frac{q}{A K T} U\right]-I_{0}\right|,
\end{aligned}
$$

where $S(k)$ is the step adjustment factor.

Relation curve of $S(k)$ against voltage $U$ is shown in Figure 10. Take $S(k)$ as the normalization factor of voltage perturbation step size. According to the actual working condition of PV cell, the perturbation step is adjusted in time, which is described as

$$
U(k+1)=U(k) \pm S(k) \text { step. }
$$

Note that step adjustment factor $S(k)$ increases sharply on the right of MPP. In order to make the MPPT algorithm able to be converged on the right of MPP in the P-U curve, here, adjustment factor is limited, $S(k) \in[0,1]$. And Figure 11 shows a flowchart of the improved MPPT algorithm.

\section{Simulation Results and Analysis}

The PV generation system consists of PV array module, MPPT module, DC/DC converter module, and so forth, which is shown in Figure 12.

The simulation conditions are as follows: short-circuit current is $3.45 \mathrm{~A}$, open-circuit voltage is $43.5 \mathrm{~V}$, maximum power point voltage is $35 \mathrm{~V}$, maximum power point current is $3.15 \mathrm{~A}$, temperature is $25^{\circ} \mathrm{C}$, the initial step is 0.005 , and simulation time is $0.6 \mathrm{~s}$. 


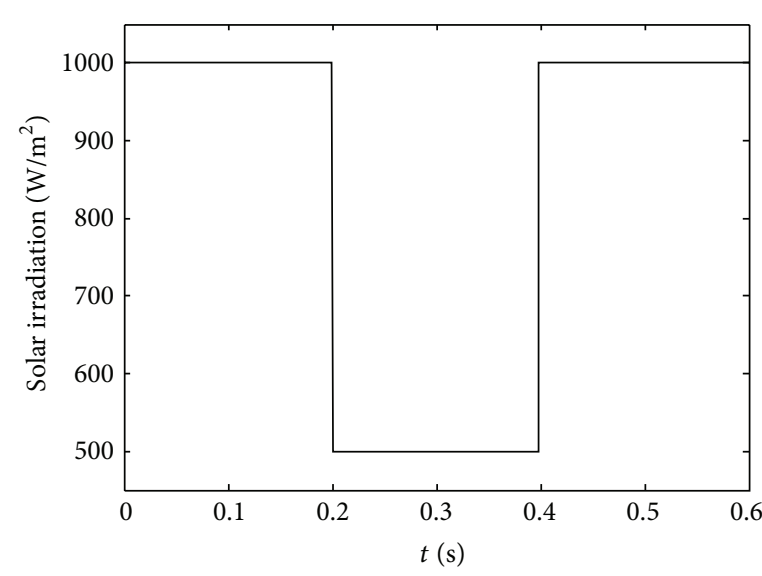

(a) The solar irradiation curve

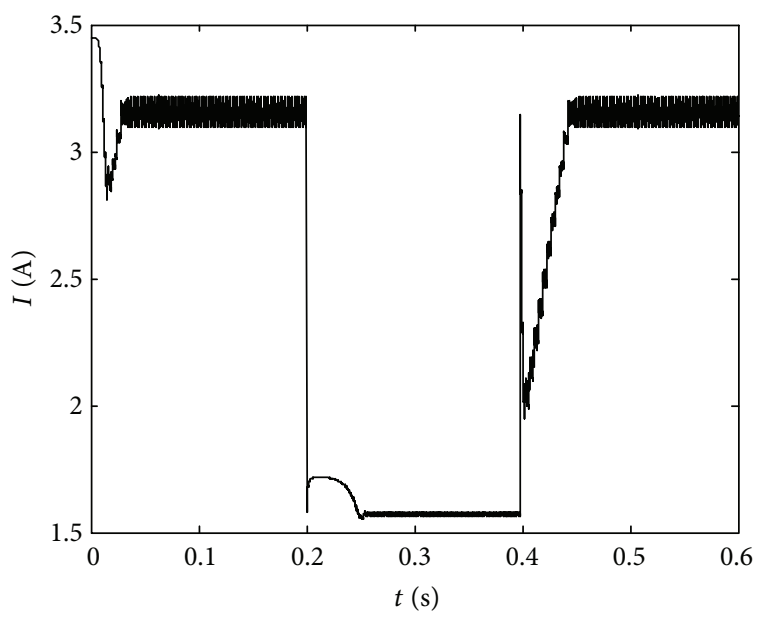

(c) The output current curve

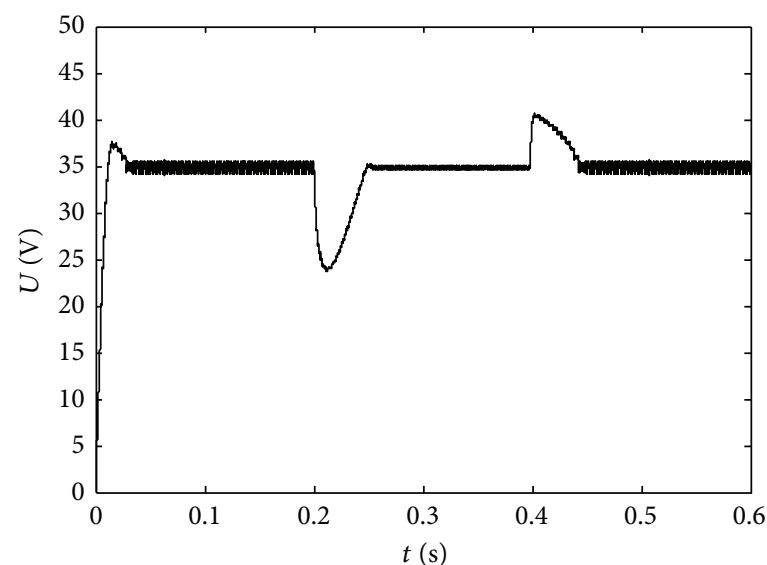

(b) The output voltage curve

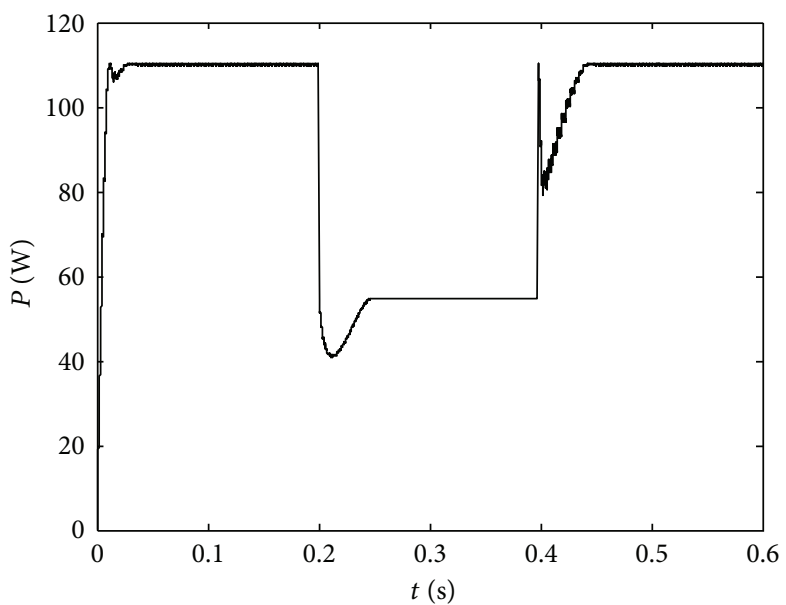

(d) The output power curve

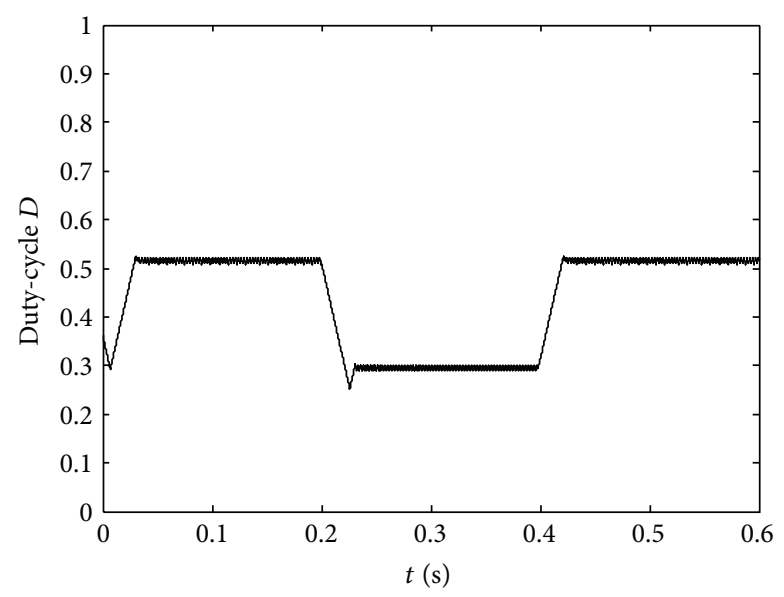

(e) The duty-cycle curve

FIGURE 13: The classical P\&O algorithm curves.

Figure 13(a) shows the curve of solar irradiation changes over $t$. Figures 13(b)-13(e) are the simulation results according to Figure 13(a), where Figure 13(b) is the output voltage curve, Figure 13(c) is the output current curve, Figure 13(d) is the output power curve, and Figure 13(e) is the dutycycle curve. The figures show that the working point reaches the maximum power point at $0.03 \mathrm{~s}$, and the maximum power is $110 \mathrm{~W}$. When solar radiation mutates, the output power is not stable and has an oscillation around MPP.

Figure 14 shows the improved MPPT algorithm simulation results. Figure 14(a) is the output voltage curve, Figure 14(b) is the output current curve, Figure 14(c) is 


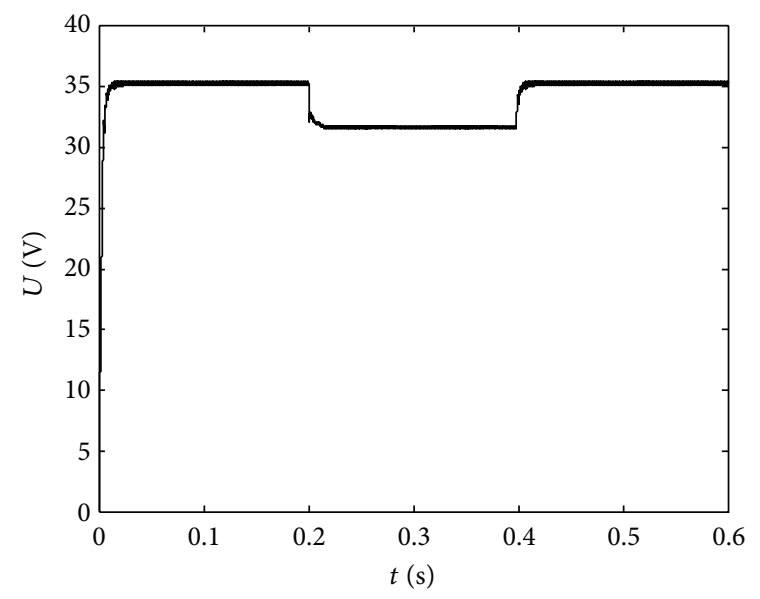

(a) The output voltage curve

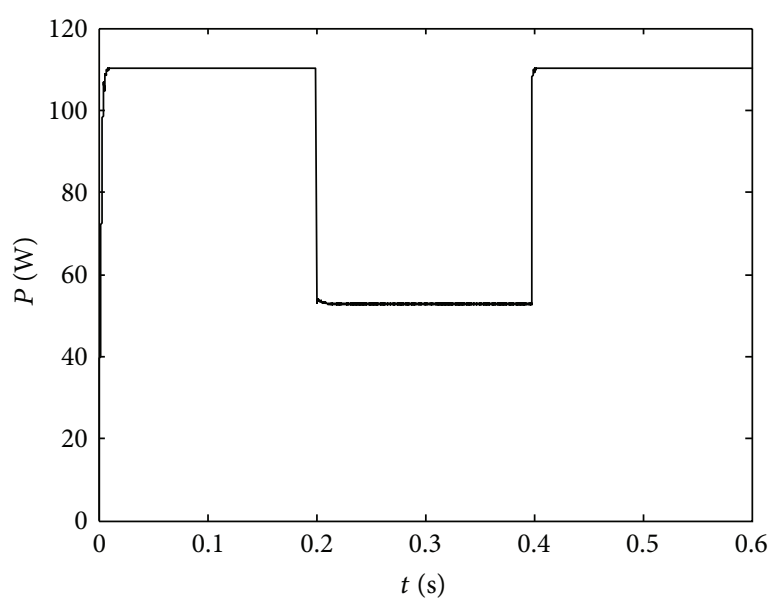

(c) The output power curve

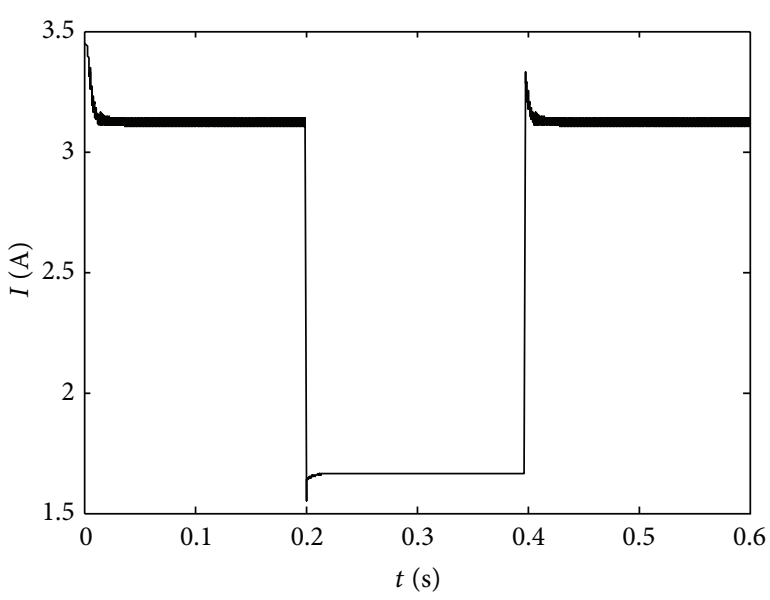

(b) The output current curve

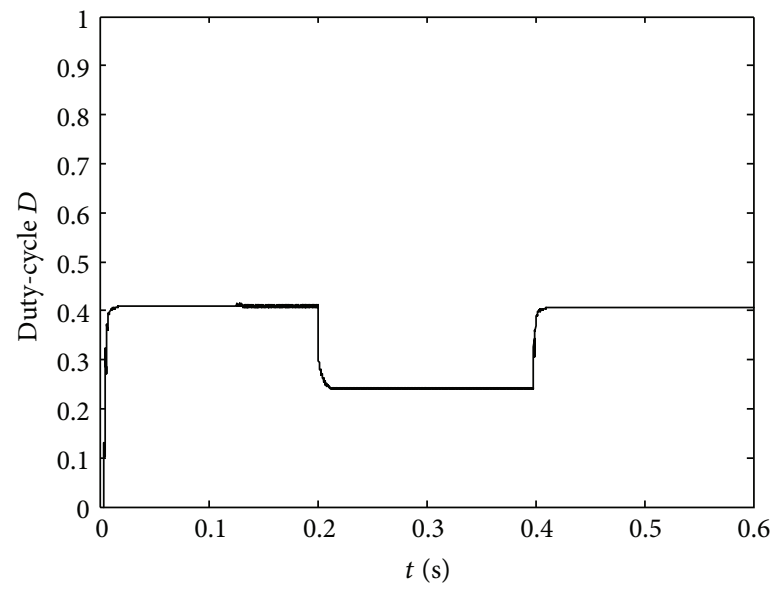

(d) The duty-cycle curve

FIgURE 14: The improved MPPT algorithm curves.

the output power curve, and Figure 14(d) is the duty-cycle curve. The figures show that MPP is tracked at $0.01 \mathrm{~s}$, and the maximum power is $110.25 \mathrm{~W}$. MPP can be tracked faster and smoother, and the fluctuation of tracking process is very small.

Compared with Figures 13 and 14, the classical $\mathrm{P} \& \mathrm{O}$ algorithm oscillates around MPP, and maximum power cannot be tracked accurately when solar irradiation mutates. With the improved MPPT algorithm, the output power curve is smoother under the same conditions, and MPP is tracked in a shorter time.

\section{Conclusion}

In this paper, the variable $\mathrm{P} \& \mathrm{O}$ MPPT algorithm based on $P-U$ curve reconstitution has been proposed to track MPP. And the proposed algorithm has been verified with the simulation. Compared with the classical $\mathrm{P} \& \mathrm{O}$ algorithm, results show that MPP is tracked accurately with the proposed algorithm, and the misjudgment is eliminated effectively, and the contradiction between tracking speed and accuracy is also relieved. The simulation result verifies the effectiveness of the proposed algorithm.

\section{Competing Interests}

The authors declare that they have no competing interests.

\section{Acknowledgments}

This work was supported by the National Natural Science Foundation of China under Grant E070602/51507155, China Postdoctoral Science Foundation under Grant 2013M541990, Key Project of Science and Technology Research of Education Department of Henan Province under Grant 14A470002, and Fundamental and Cutting-Edge Technology Research Project of Henan Province under Grant 152300410046.

\section{References}

[1] M. A. G. de Brito, L. Galotto, L. P. Sampaio, G. de Azevedoe Melo, and C. A. Canesin, "Evaluation of the main MPPT techniques for photovoltaic applications," IEEE Transactions on Industrial Electronics, vol. 60, no. 3, pp. 1156-1167, 2010. 
[2] D. Zhou and C. Chen, "Maximum power point tracking strategy based on modified variable step-size incremental conductance algorithm," Power System Technology, vol. 39, no. 6, pp. 14921498, 2015.

[3] Y. Yang and K. Zhou, "Photovoltaic cell modeling and MPPT control strategies," Transactions of China Electrotechnical Society, vol. 26, no. 1, pp. 229-234, 2011.

[4] G.-C. Hsieh, H.-I. Hsieh, C.-Y. Tsai, and C.-H. Wang, "Photovoltaic power-increment-aided incremental-conductance MPPT with two-phased tracking," IEEE Transactions on Power Electronics, vol. 28, no. 6, pp. 2895-2911, 2013.

[5] Z. M. Dalala, Z. U. Zahid, and J.-S. Lai, "New overall control strategy for small-scale wecs in mppt and stall regions with mode transfer control," IEEE Transactions on Energy Conversion, vol. 28, no. 4, pp. 1082-1092, 2013.

[6] M. A. Elgendy, B. Zahawi, and D. J. Atkinson, "Assessment of perturb and observe MPPT algorithm implementation techniques for PV pumping applications," IEEE Transactions on Sustainable Energy, vol. 3, no. 1, pp. 21-33, 2012.

[7] B. Liu, S. Duan, F. Liu, and P. Xu, "Photovoltaic array maximum power point tracking based on improved perturbation and observation method," Power System Technology, vol. 2, no. 46, pp. 91-94, 2009.

[8] R. Garg, A. Singh, and S. Gupta, "PV cell models and dynamic simulation of MPPT trackers in MATLAB," in Proceedings of the 8th International Conference on Computing for Sustainable Global Development (INDIACom '14), pp. 6-12, New Delhi, India, March 2014.

[9] Q. Mei, M. Shan, L. Liu, and J. M. Guerrero, "A novel improved variable step-size incremental-resistance MPPT method for PV systems," IEEE Transactions on Industrial Electronics, vol. 58, no. 6, pp. 2427-2434, 2011.

[10] Z. Peng, J. He, G. Ma, C. Zhou, and F. Li, "Sampling period optimization design of output power of photovoltaic power generation MPPT systems," Proceedings of the Chinese Society of Electrical Engineering, vol. 32, no. 34, pp. 24-29, 2012.

[11] D. Sera, L. Mathe, T. Kerekes, S. V. Spataru, and R. Teodorescu, "On the perturb-and-observe and incremental conductance mppt methods for PV systems," IEEE Journal of Photovoltaics, vol. 3, no. 3, pp. 1070-1078, 2013.

[12] R. Faraji, A. Rouholamini, H. R. Naji, R. Fadaeinedjad, and M. R. Chavoshian, "FPGA-based real time incremental conductance maximum power point tracking controller for photovoltaic systems," IET Power Electronics, vol. 7, no. 5, pp. 12941304, 2014.

[13] A. Hmidet, N. Rebei, and O. Hasnaoui, "Experimental studies and performance evaluation of MPPT control strategies for solar-powered water pumps," in Proceedings of the 10th International Conference on Ecological Vehicles and Renewable Energies (EVER '15), pp. 1-12, Monte-Carlo, Monaco, April 2015.

[14] Y. Zhou, F. Liu, J. Yin, and S. Duan, "Study on realizing MPPT by improved incremental conductance method with variable stepsize," in Proceedings of the 3rd IEEE Conference on Industrial Electronics and Applications (ICIEA '08), pp. 547-550, Singapore, June 2008.

[15] D. Wu and X. Wang, "A photovoltaic MPPT fuzzy controlling algorithm," Acta Energiae Solaris Sinica, vol. 32, no. 6, pp. 808813, 2011.

[16] A. Costabeber, M. Carraro, and M. Zigliotto, "Convergence analysis and tuning of a sliding-mode ripple-correlation MPPT," IEEE Transactions on Energy Conversion, vol. 30, no. 2, pp. 696706, 2015.
[17] S. Li, X. Zhang, H. Zhang, W. Zhao, and H. Ni, “Global MPPT method based on power closed-loop control and PSO algorithm," Proceedings of the Chinese Society of Electrical Engineering, vol. 34, no. 28, pp. 4809-4816, 2014.

[18] P. Kumar, G. Jain, and D. K. Palwalia, "Genetic algorithm based maximum power tracking in solar power generation," in Proceedings of the International Conference on Power and Advanced Control Engineering (ICPACE '15), pp. 1-6, Bengaluru, India, August 2015. 


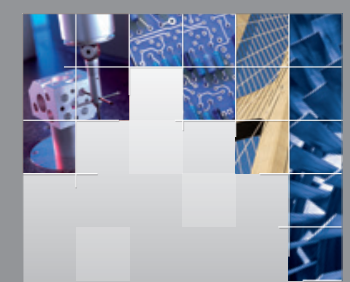

\section{Enfincering}
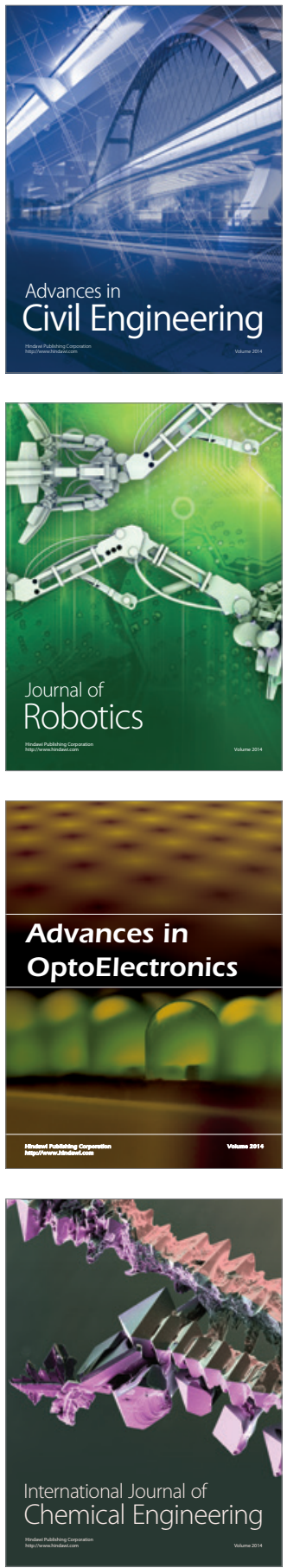

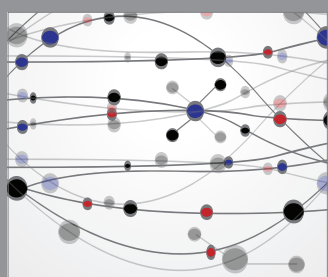

The Scientific World Journal

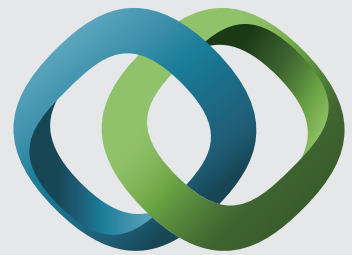

\section{Hindawi}

Submit your manuscripts at

http://www.hindawi.com
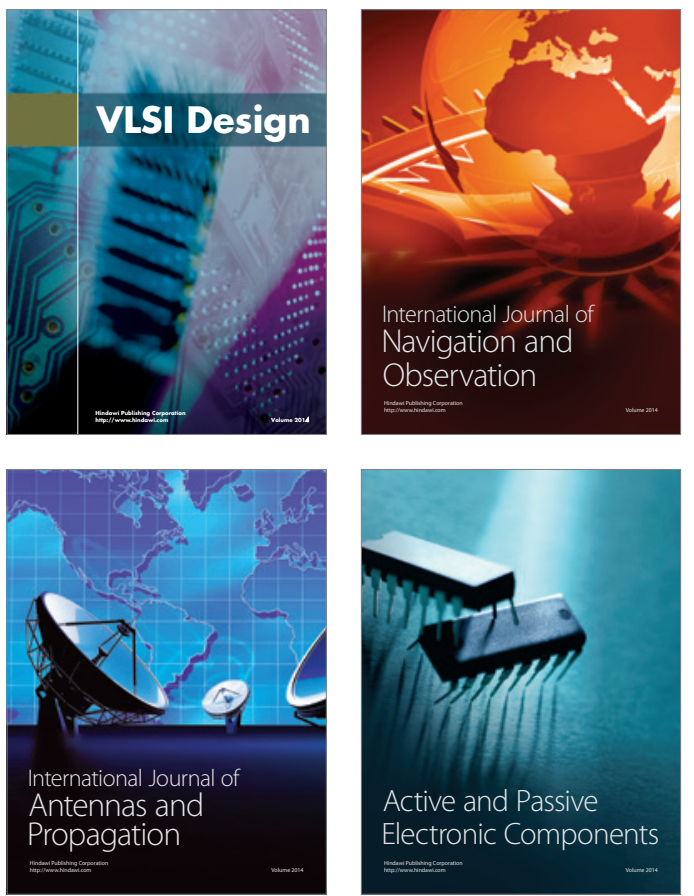
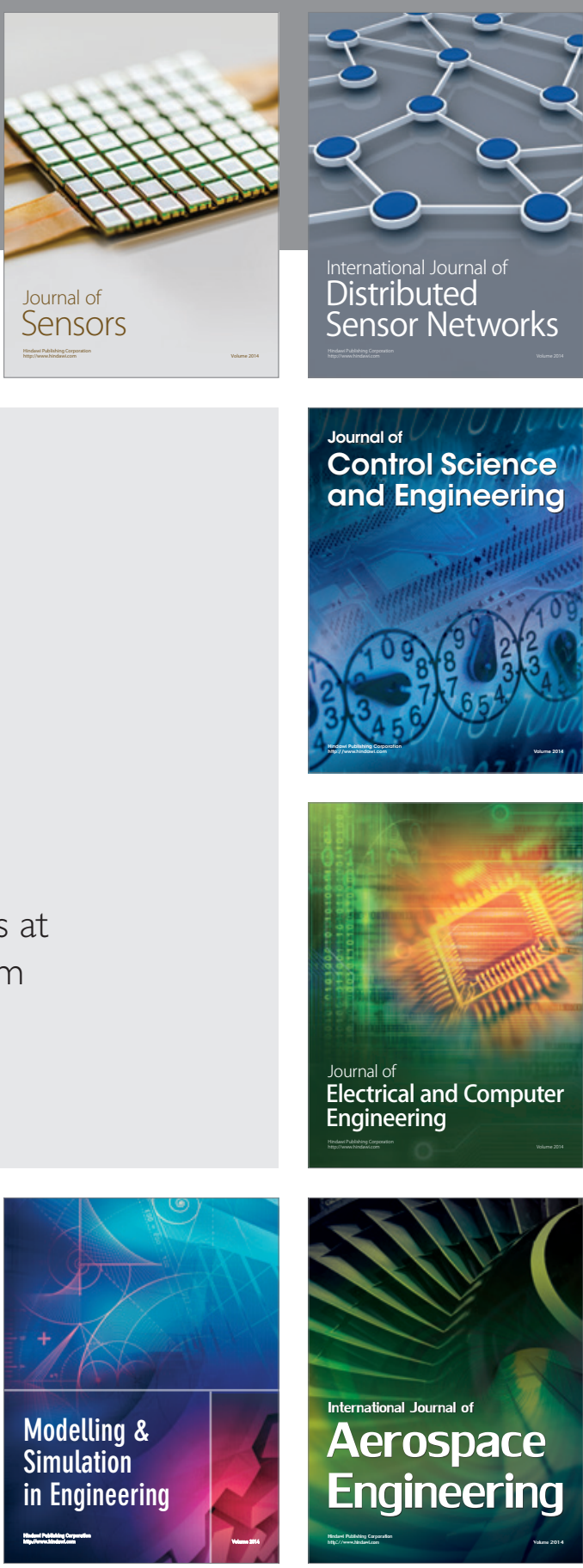

International Journal of

Distributed

Sensor Networks

Journal of

Control Science

and Engineering
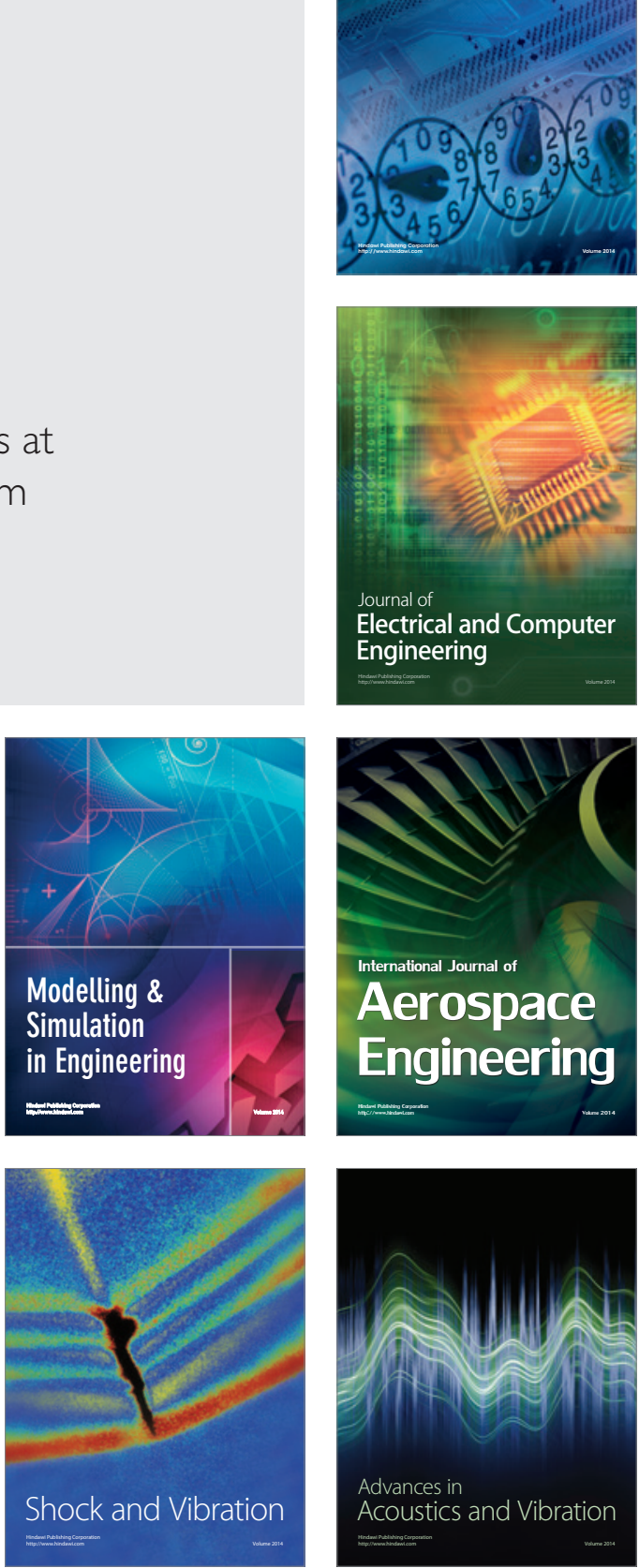